\section{L'Actualité économique}

L'ACTUALITÉ ÉCONOMIQUE

International Commodity Agreements, par WILLIAM-E. HAVILAND. Une brochure, $5^{1 / 2}$ po. $X$ 81/2, 81 pages. CANADIAN-AMERICAN COMMITTEE, 1963. (\$2.00)

\title{
B. B.
}

Volume 40, numéro 3, octobre-décembre 1964

URI : https://id.erudit.org/iderudit/1003395ar

DOI : https://doi.org/10.7202/1003395ar

Aller au sommaire du numéro

Éditeur(s)

HEC Montréal

ISSN

0001-771X (imprimé)

1710-3991 (numérique)

Découvrir la revue

Citer ce compte rendu

B., B. (1964). Compte rendu de [International Commodity Agreements, par WILLIAM-E. HAVILAND. Une brochure, $5 \frac{11}{2}$ po. X $8 \frac{1}{2}, 2,81$ pages. CANADIAN-AMERICAN COMMITTEE, 1963. (\$2.00)]. L'Actualité économique, 40(3), 625-625. https://doi.org/10.7202/1003395ar d'utilisation que vous pouvez consulter en ligne.

https://apropos.erudit.org/fr/usagers/politique-dutilisation/ 


\section{LES LIVRES}

récupération des sols dans le nord-ouest du pays et décentralisation industrielle.

Les auteurs ont fait passablement le tour de l'organisation de la planification en Suède. L'étude nous laisse toutefois deviner les buts ultimes de cette planification : le plein emploi. Les auteurs ne semblent pas conscients de l'importance du « National Market Labour Board» dans l'élaboration et l'application de la planification suédoise.

Les conclusions qui se dégagent de cette étude peuvent laisser songeurs les lecteurs avertis. La croissance européenne a été faible pendant les années 1938 à 1950 tandis qu'en Amérique du Nord la croissance était rapide. Après 1950 on retrouve la situation inverse. Les auteurs semblent attribuer ce renversement de situation à la planification sans analyser les effets de la guerre et de l'occupation militaire dans les pays européens et en Amérique du Nord.

En général, la publication est assez bonne mais contient certaines imprécisions qui peuvent laisser des doutes sur les études présentées. Il semble que les auteurs aient voulu trop condenser les notions qu'ils voulaient nous apporter.

R. J.

International Commodity Agreements, par William-E. Haviland. Une brochure, $51 / 2$ po. $\times 81 / 2,81$ pages. - CANADIAN-AMERICAN CoMmittee, 1963. ( $\$ 2.00)$.

On connait l'importance, particulièrement pour les pays sous-développés, de la stabilisation des cours des matières premières. Cette question n'est pas, non plus, sans intérêt pour le Canada, gros exportateur de produits primaires.

L'auteur expose donc le fonctionnement d'un certain nombre d'accords présentement en opération, et dont le but est d'arriver à limiter les fluctuations des cours : accord sur le blé, accord sur le café, accord sur le sucre, sur l'étain, sur l'huile d'olive, sur le cacao, sur le plomb et le zinc, etc. Dans un troisième chapitre, il analyse plus en détail les caractéristiques de ces accords et les problèmes qu'ils posent (conflits d'intérêts, etc.). Il expose ensuite les principales mesures que devrait comporter une politique mondiale destinée à stabiliser les cours des matières premières, et termine par une discussion des avantages que le Canada pourrait retirer de la résolution d'un problème comme celui-ci, et des obligations qu'il doit assumer pour tenter de trouver cette solution. On trouvera également une bonne bibliographie sur la question.

B. B.

L'Économie britannique, par Claude Chaline (collection * Que sais-je ? »). Un vol., $41 / 2$ po. $\times 7$, broché, 128 pages. - Presses universitaires De France, 108, boulevard Saint-Germain, Paris, 1963.

Cet ouvrage constitue un très bon résumé de la situation économique de la Grande-Bretagne. Après avoir exposé les principales données de base de l'économie britannique, l'auteur aborde l'aspect du commerce extérieur, du transport, de la localisation industrielle et de la pêche. « Le renouvellement économique » 